\title{
Linus Pauling
}

LIKE MICHAEL FARADAY, Linus Pauling was born poor; he struggled at menial jobs to support himself at high school and while studying for a degree in chemical engineering at the Oregon Agricultural College. All the same, he became interested in the electron theory of valence when he was only eighteen, and after this he "continued to hope that the empirical information about the properties of substances could eventually be encompassed in a theory of the structure of molecules". Fulfillment of his hope began to take shape in 1926 when he spent a postdoctoral year at Munich with Germany's greatest teacher of theoretical physics, Arnold Sommerfeld, just as Erwin Schrödinger published his first papers on wave mechanics. Sommerfeld immediately recognized their importance and gave a course of lectures on them. Having absorbed what knowledge he could in Munich, Pauling next went to Zürich to work with Schrödinger himself, but found his stay disappointing, because Schrödinger liked to work all by himself and took little notice of him. Pauling then returned to the California Institute of 'Technology at Pasadena where he had taken his doctoral degree and started his work on the nature of the chemical bond.

One of his first papers on the chemical bond was revolutionary, because it explained the tetrahedral coordination of carbon and the square or octahedral coordination of transition metals on wave mechanical principles. The introduction conveys something of the flavour of his paper: "During the last four years the problem of the nature of the chemical bond has been attacked by theoretical physicists, especially Heitler and London, by the application of quantum mechanics. This work has led to an approximate theoretical calculation of the energy of formation and other properties of very simple molecules, such as $\mathrm{H}_{2}$, and has also

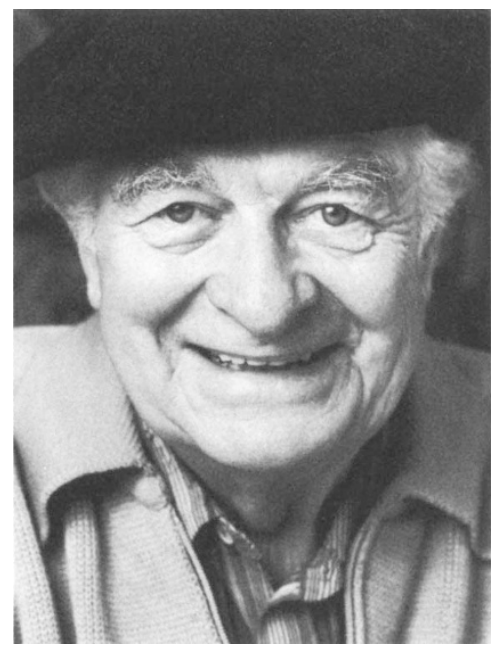

\section{1-1994}

provided a formal justification for the rules set up in part by G.N.Lewis for the electron pair bond. In the following paper it will be shown that many more results of chemical significance can be obtained from the quantum mechanics equation, permitting the formulation of an extensive set of rules for the electron-pair bond supplementing those of Lewis. Those rules provide information regarding the relative strengths of bonds formed by different atoms, the angles between bonds, free rotation, or lack of free rotation about bond axes, the relation between the quantum numbers of bonding electrons and the number and spatial arrangement of bonds, and so on. A complete theory of the magnetic moments of molecules and complex ions is also developed, and it is shown that for many compounds involving elements of the transition group this theory together with the rules of electron pair bonds leads to a unique assignment of electron structures as well as a definite determination of the type of bonds involved". Nothing like this had been done before.

In a later paper Pauling applied to chemistry the concept of reso- nance originally introduced by Heisenberg into quantum mechanics. "It is found that there are many substances whose properties cannot be accounted for by means of a single electronic structure of the valence bond type, but which can be fitted into the scheme of classical valence theory by the consideration of resonance among two or more structures". Benzene was the prime example.

Pauling's valence bond theory established the relationship between interatomic distances, mostly derived from accurate crystallographic data, and bond energies, on which much of his successful interpretation of the chemical properties of organic compounds was based. With that in mind, he founded at Pasadena an outstanding research school of structural chemistry. Pauling's Munich experience also led him to write an Introduction to Quantum Mechanics for chemists, together with E. Bright Wilson, which was first published in 1935 and remains a useful classic.

As a chemistry student in Vienna in the nineteen thirties I had been made to memorize the 759 pages of Karl Hotffman's Inorganic Chemistry and the 866 pages of Paul Karrer's Organic Chemistry. I looked upon such tasks as feats of endurance which gave me a certain sporting satisfaction - like walking from Land's End to John O'Groat's - but they gave me little intellectual satisfaction, because the books did not explain the properties of matter. Why does water freeze at $0^{\circ} \mathrm{C}$ and methane at $-184^{\circ}$ $\mathrm{C}$ ? Why does one form of selenium melt at a temperature $76^{\circ} \mathrm{C}$ higher than the other? Why is sulphur soft and diamond hard? Why is one form of silica, quartz, optically active, while the two others, tridymite and crystoballite, are not? Why is salicylic acid stronger than benzoic acid? No such questions were answered for me.

In 1936 I became a research stu- 


\section{obituary}

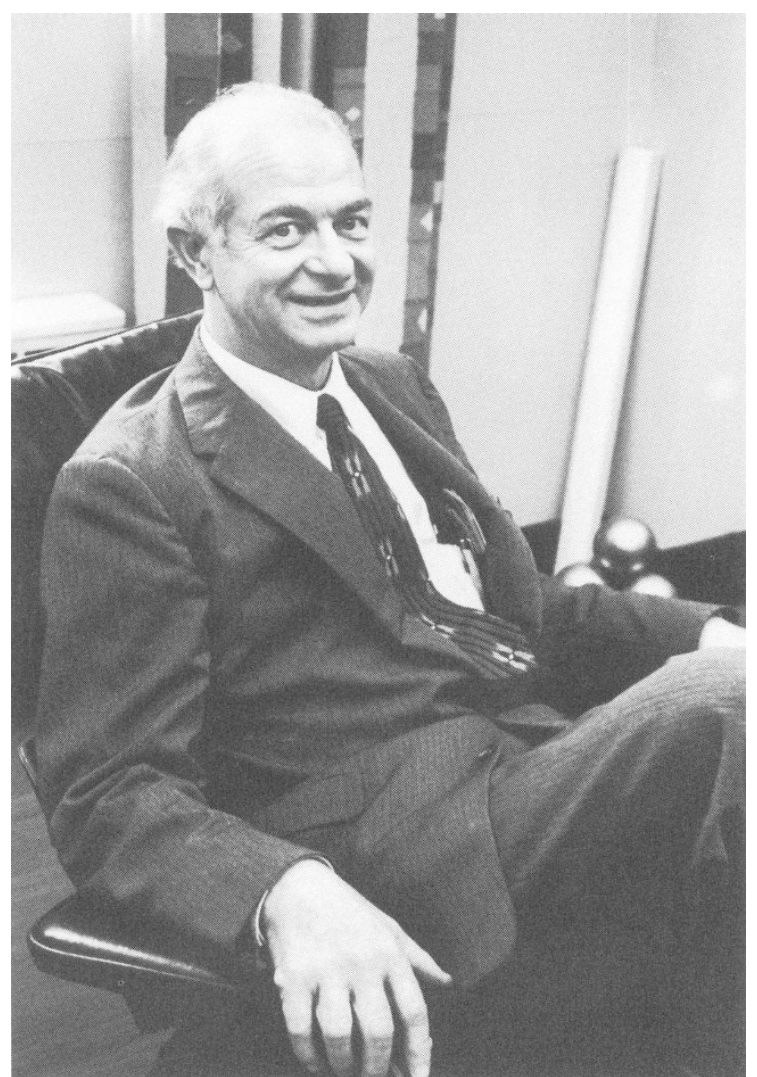

dent in X-ray crystallography at Cambridge. For Christmas, 1939, a girl friend gave me a book token which I used to buy Linus Pauling's recently published Nature of the Chemical Bond. His book transformed the chemical flatland of my earlier textbooks into a world of three-dimensional structures. It stated that "the properties of a substance depend in part upon the type of bonds between its atoms and in part on the atomic arrangement and the distribution of bonds", and it proceeded to illustrate this theme with many striking examples. For instance, Pauling discusses the cause of a discontinuity in the melting points of the fluorides of the second row elements thus: "An abrupt change in properties in a series of compounds, such as in the melting points or boiling points of metal halides has sometimes been considered to indicate an abrupt change in bond type. Thus of the fluorides of the second-row elements, those of high melting points, have been described as salts, and the others as covalent compounds; and the drop in melting point of $1100^{\circ} \mathrm{C}$ in going from aluminium fluoride to silicon fluoride has been interpreted as showing that the bonds change sharply from the extreme ionic type to the extreme covalent type ${ }^{1}$. I consider the bonds in aluminium fluoride to be only slightly different in character from those in silicon fluoride and attribute the abrupt changes in properties to a change in the nature of the atomic arrangements ${ }^{2}$. In $\mathrm{NaF}, \mathrm{MgF}_{2}$ and $\mathrm{AlF}_{3}$ each of the metal atoms is surrounded by an octahedron of fluorine atoms, and the stoichiometric relations then require that each fluorine atom be held jointly by several metal atoms. In each of these crystals the molecules are thus combined into giant polymers, and the processes of fusion and vaporization can take place only by breaking the strong chemical bonds between metal and nonmetal atoms: as a consequence the substances have high melting points and boiling points. The stable coordination number of silicon relative to fluorine is, on the other hand, four, so that the $\mathrm{SiF}_{4}$ molecule has little tendency to form polymers. The crystals of silicon fluoride consist of $\mathrm{SiF}_{4}$ molecules piled together and held together only by weak van der Waals forces". Characteristically for Pauling's showmanship, the first reference is to N.V. Sidgwick's classic The Electronic Theory of Valency, and the second reference to one of his own papers. By such examples Pauling's book fortified my belief, already inspired by J.D. Bernal, that knowledge of three-dimensional structure is all important and that the functions of living cells will never be understood without knowing the structures of the large molecules composing them.

In my physical chemistry practical at Vienna I had had to prove to myself that acetic acid in solution forms dimers, but it needed Pauling to drive home the importance of the hydrogen bonds that are responsible for their formation: "Although the hydrogen bond is not strong it has great significance in determining the properties of substances. Because of its smal bond energy and the small activation energy involved in its formation and rupture, the hydrogen bond is especially suited to play a part in reactions occurring at normal temperatures. It has been recognized that hydrogen bonds restrain protein molecules to their native configurations, and I believe that as the methods of structural chemistry are further applied to physiological problems it will be found that the significance of the hydrogen bond for physiology is greater than that of any other single structural feature". This was a remarkable prophecy made when nothing was known as yet about protein structure.

Pauling's imaginative approach, his synthesis of structural, theoretical and practical chemistry, his capacity for drawing on a wide variety of observations to prove his generalizations, and his vivid writing drew the dry facts of chemistry together into a coherent intellectual fabric for me and thousands of other students for the first time.

I first met Pauling ten years after I had read his book and was intrigued by his lectures, where he would reel off the top of his head atomic radii, interatomic distances and bond energies with the gusto of an organist playing a Bach fugue; afterwards he would look around for applause, as I had seen Bertrand Russell do after quoting one of his elegant metaphors. Pauling's lectures reinforced the chief message of his book: to understand the properties of molecules, not only must you know their structures, but you must know them accurately.

Besides directing many people's research, Pauling used to deliver a freshmen's introductory course of lectures which he first published as a textbook of General Chemistry in 1947. Its 1970 edition contains over 900 pages; it begins with an introduction to the atomic and molecular structure of matter, covers most important aspects of physical and inorganic chemistry, touches on the elements of organic and biochemistry and ends with nuclear chemistry. The lectures were spec- 
tacular and often dramatic. Jack Dunitz described one to me: A large beaker filled with what looked like water stood on the bench. Pauling entered, picked a cube of sodium metal from a bottle, tossed it from hand to hand (done safely if your hands are dry) and warned of its violently explosive reaction with water. He then threw it into the beaker. As students cowered in fear of an explosion, he said nonchalantly "but its reaction with alcohol is much milder".

Pauling also made several important excursions into biological subjects; the first was into immunology. He conceived the idea that antibodies adapt their structures to those of antigens by a refolding of their polypeptide chains in solution: he was wrong, but it was a reasonable theory before anything was known about the genetic basis of protein structure. He next became interested in haemoglobin. Having read that Faraday found blood to be diamagnetic despite iron and oxygen being paramagnetic, he told his student Charles Coryell to measure the magnetic susceptibility of haemoglobin in the presence and absence of oxygen. In 1936, Coryell found oxyhaemoglobin to be diamagnetic, and deoxyhaemoglobin to be paramagnetic with a spin of $S=2$. Forty years later I asked Pauling what made him think of this experiment which later turned out to have been crucial for an understanding of haemoglobin's function. Pauling replied that it had not been clear whether oxygen formed a chemical bond with the iron in haemoglobin or whether it was merely being adsorbed, and he thought that formation of a chemical bond might be accompanied by a magnetic change. In 1970 I found that the spin transition of the iron is the trigger for the allosteric change that accompanies the reaction of haemoglobin with oxygen.

In 1949 someone got Pauling interested in sickle cell disease - a genetic disorder affecting mainly black people - which causes the red cells to be distorted to various sickled shapes on loss of oxygen. Pauling suggested to his young collaborators ltano, Singer and Wells that they should examine the electrophoretic mobilities of normal and sickle cell haemoglobin. They found them to be different, because sickle cell haemoglobin carries two fewer negative charges than normal haemoglobin. Pauling published this result in Science under the dramatic title: "Sickle cell haemoglobin, a molecular disease". This paper led Vernon Ingram and John Hunt in my Medical Research Council Unit in Cambridge to show that sickle cell haemoglobin differed from the normal protein merely by the replacement of a single pair of glutamic acid resi- dues by valines. Their discovery of the effect of a genetic mutation on the amino acid sequence of a protein posed poignantly the question of the genetic code, which Crick, Brenner and their colleagues answered a few years later with their demonstration that triplets of nucleotides determine the amino acid sequence of proteins.

Among biochemists, Pauling is most famous for his discovery of the $\alpha$-helix which came as the culmination of X-ray analyses of the structures of amino acids pioneered in the 1930's and 40's by his collaborators Robert Corey and

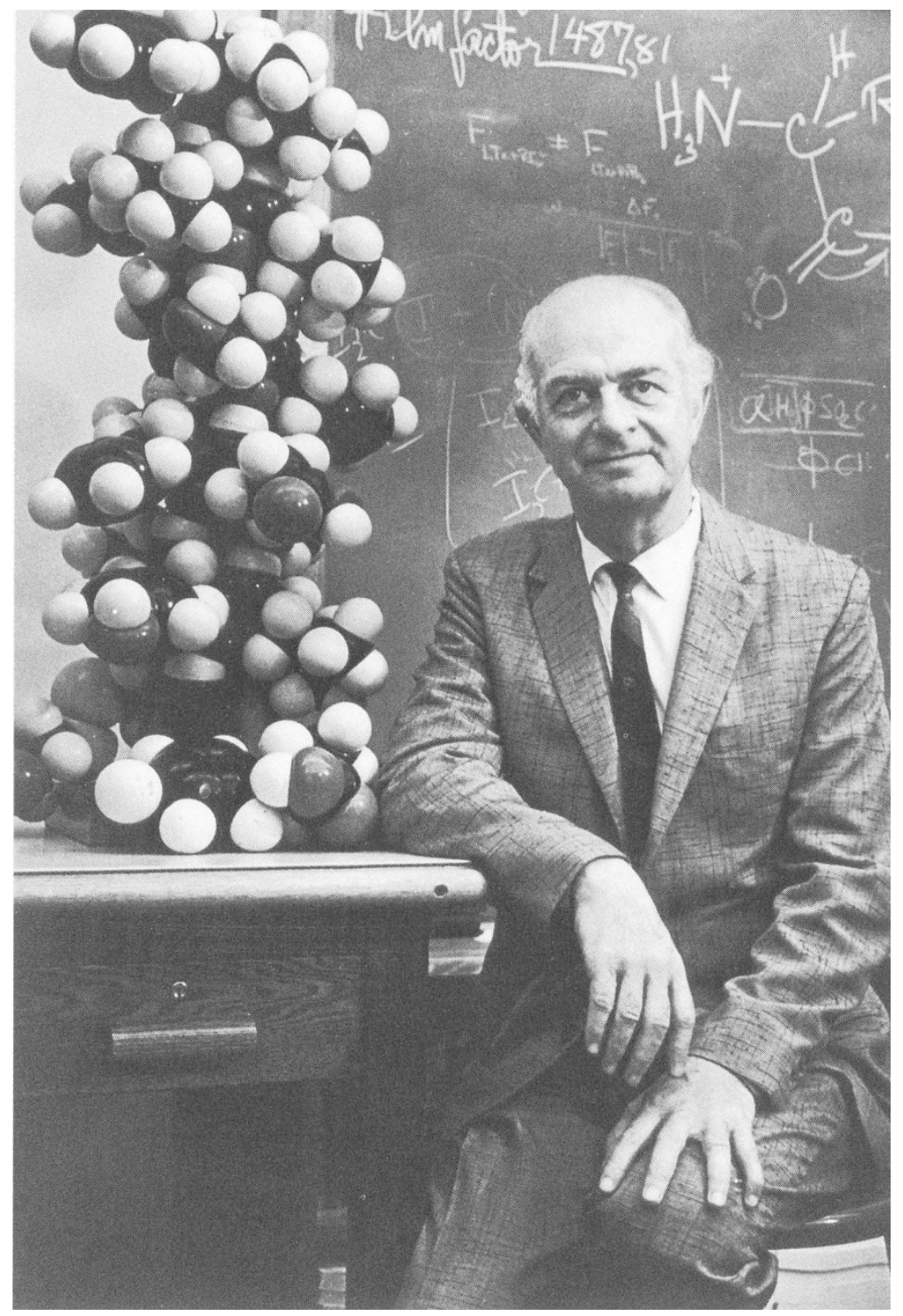

The man and his model. Linus Pauling, Professor of Chemistry, California Institute of Technology, poses beside a model of the $\alpha$-helix. 
Edward Hughes; at that time glycine, alanine and diketopiperazine presented a degree of complexity that carried X-ray analysis to the very limits of the possible. The results provided Pauling with the stereochemical data he needed for the interpretation of the meagre $\mathrm{X}$-ray diffraction patterns which Bill Astbury at Leeds had obtained from protein fibres such as hair, nails and muscle. Pauling argued that in a long-chain polymer made of chemically equivalent units, all units must occupy geometrically equivalent positions, which was possible only in a helix. Further, the structure of diketopiperazine had shown that the peptide bond had partial double bond character, so that the atoms

$$
{ }_{\mathrm{C} \alpha}^{\mathrm{H}}>\mathrm{N}=\mathrm{C}>\mathrm{C}
$$

must all lie in a plane. Finally, all amido ( $\mathrm{NH}$ ) groups should form hydrogen bonds with carbonyl (CO) groups. Lying in bed with 'flu in Oxford in 1948, Pauling amused himself by building a paper chain of planar peptides and found a satisfactory structure by folding them into a helix with 3.6 residues per turn. Shortly after this he visited Kendrew and myself in Cambridge. Ignorant of his Oxford experiment, I proudly showed him my three-dimensional Patterson of haemoglobin which indicated that its polypeptide chain was folded in the same way as Astbury's fibres, but to my disappointment Pauling made no comment; he did not announce his discovery until the delivery of a dramatic lecture at Pasadena in the following year. It helped to earn him the Nobel Prize in Chemistry in 1954, but he had really deserved it for his many other outstanding contributions to chemistry much earlier.

After the $\alpha$-helix Pauling produced one more fundamental paper. When the amino acid sequences of the haemoglobins of different animals were beginning to be known, it became clear that the number of amino acid substitutions increased with the distance between species on the evolutionary tree. This inspired Pauling and his young collaborator Emile Zuckerkandl to propose the existence of an evolutionary clock which ticks at the rate of about one amino acid substitution per hundred residues per 5 million years. Like many of Pauling's papers this one initiated an entire new field of research which has since occupied many other scientists' lives. Pauling continued publishing papers almost to the end of his life, but nothing as fundamental as his earlier work appeared, possibly because he became too preoccupied, first with the threat of nuclear war and later with vitamin $C$.

In the McCarthy era, Pauling's anti-nuclear stance earned him the reputation of a 'red'. In 1952, when the Royal Society organized a Discussion on the Structure of Proteins at which Pauling should have been the principal contributor, he could not come because the State Department had withdrawn his passport. In 1954, the English philosopher Bertrand RusselI gave Christmas lectures on the radio warning of the dangers of nuclear war. Next year he drew up a manifesto against nuclear arms which Albert Einstein signed a few days before his death. This concluded with the words: "There lies before us if we choose, continual progress in happiness, knowledge and wisdom. Shall we, instead, choose death, because we cannot forget our quarrels? We appeal, as human beings, to human beings: remember your humanity and forget the rest. If you can do so, the way lies open to a new paradise; if you cannot, there lies before you the risk of universal death". Pauling signed this manifesto together with seven prominent physicists and the geneticist Hermann Muller; it led to the convening of the first Pugwash Conference at which Soviet and Western scientists discussed measures to reduce the dangers of nuclear war. In 1958, Pauling published a book: No More War and handed to Dag Hammarskjöld, the Secretary General of the United Nations, a petition signed by 9235 scientists "urging that an international agreement to stop the testing of nuclear weapons be made now....inasmuch as it is the scientists who have some measure of the complex factors involved in the problem, such as the magnitude of the genetic and somatic effects of the released radioactive materials". In May 1961 Pauling organized a conference of forty scientists on nuclear disarmament in Oslo, and afterwards led hundreds of people in a torchlight procession against nuclear war through the streets of that city. His campaign, conducted with the same panache as his lectures on chemistry, made a vital contribution to the conclusion of the atmospheric test ban in 1963 and won him the Nobel Prize for Peace in December of that year. He also campaigned against the war in Vietnam, undeterred by being called a traitor.

In 1942 Pauling contracted a severe kidney disease which he thought he had cured with massive doses of vitamin $C$. This may have sparked off his idea that huge doses of vitamin $\mathrm{C}$ were vital for health, and that they cured the common cold and even cancer. Chemists shops in Britain still sell vitamin C as "Linus Powder", of which he swallowed about eighteen grammes every day; probably about $100 \mathrm{mil}$ ligrams would have been absorbed and the rest excreted. Ascorbic acid is a scavenger of free radicals and a deficiency of it may therefore increase the likelihood of cancer, but there is no solid evidence that such massive doses have any prophylactic effect. To me it seems tragic that this should have become one of Pauling's major preoccupations for the last 25 years of his life and spoilt his great reputation as a chemist. Perhaps it was related to his greatest failing, his vanity. When anybody contradicted Einstein, he thought it over, and if he found he was wrong, he was delighted, because he felt he had escaped from an error, and that he now knew better than before, but Pauling would never admit that he might have been wrong. When, after reading Pauling's and Corey's paper on the $\alpha$-helix, I discovered an X-ray reflection at $1.5 \AA$ spacing from planes perpendicular to the axis of protein fibres which ex- 
cluded all conformations other than the $\alpha$-helix. I thought he would be pleased, but no, he attacked me furiously, because he could not bear the idea that someone else had thought of a test for the $\alpha$-helix of which he had not thought himself. I was glad when he forgot his anger later and became a good friend.

Pauling's fundamental contributions to chemistry cover a tre-

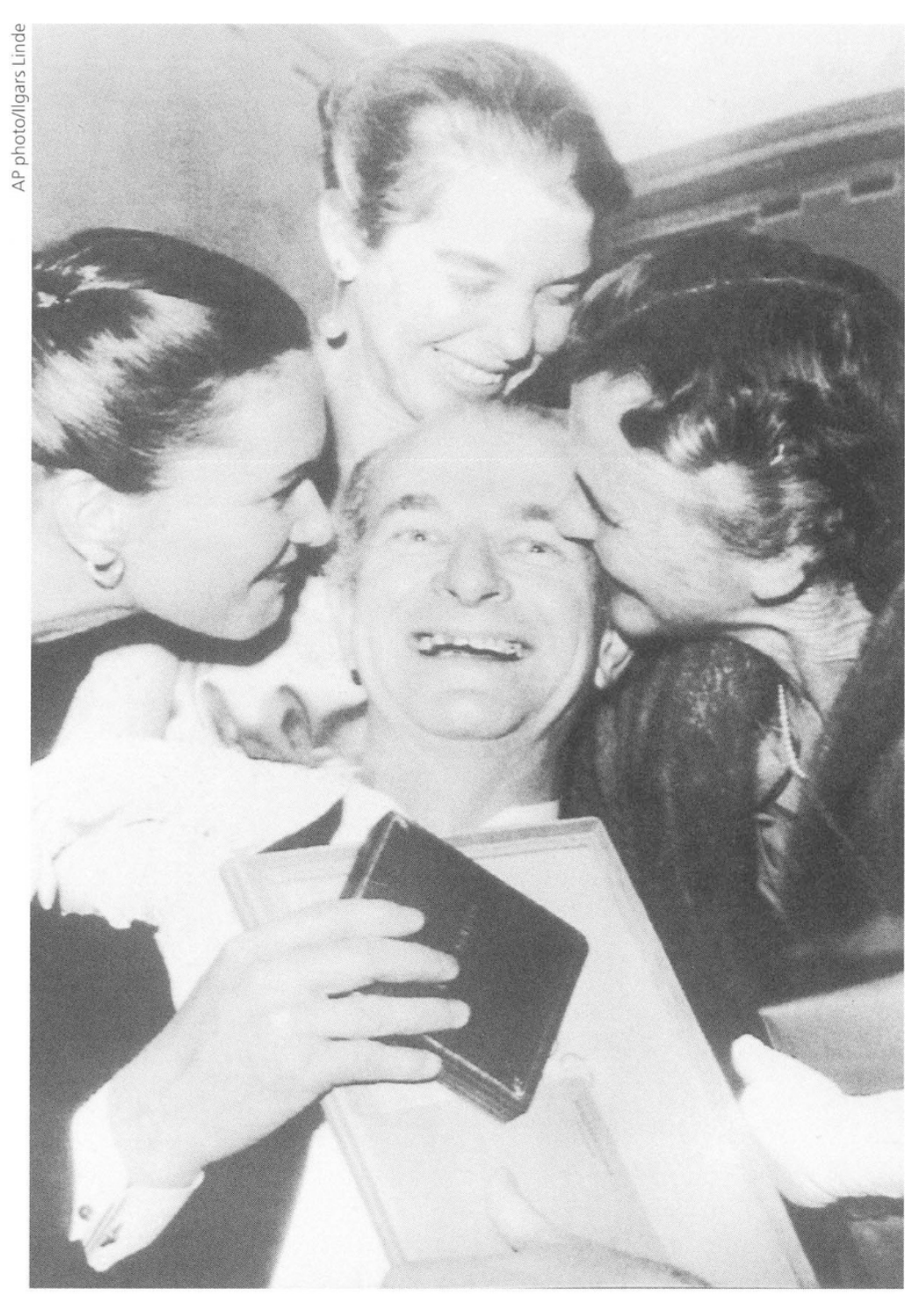

December 10, 1954: celebrations after Linus wins the Nobel Prize for Chemistry.

From left: daughter-in-law Anita; daughter Linda; and wife Ava Helen Miller Pauling.

mendous range, and their influence on generations of young chemists was enormous. In the years between 1930 and 1940 he helped to transform chemistry from a largely phenomenological subject to one based firmly on structural and quantum mechanical principles. In later years the valence bond and resonance theories which formed the theoretical backbone of Pauling's work were supplemented by R.S Mulliken's molecular orbital theory, which provided a deeper understanding of chemical bonding. For instance, it allowed C. Longuet-Higgins and W. Lipscomb to predict and explain the structures of the boranes, which would not have been possible on the basis of Pauling's concepts. Nevertheless resonance and hybridization have remained part of the everyday vocabulary of chemists and are still used, for example, to explain the planarity of the peptide bond. Many of us regard Pauling as the greatest chemist of the century.

\section{M.F. Perutz}

MRC Laboratory of Molecular Biology

Hills Road

Cambridge CB2 2QH England

Linus Pauling: born 28 February, 1901; Nobel Prize for Chemistry, 1954; Nobel Peace Prize for 1962, 1963; selected publications: The Nature of the Chemical Bond, 1939 (3rd ed., 1960); College Chemistry, 1950 (3rd ed., 1964); No More War!, 1958 (revised, 1962). Married 1923 Ava Helen Miller (died 1981); died 19 August, 1994. 